\title{
Polyphenols from Wine Lees as a Novel Functional Bioactive Compound in the Protection Against Oxidative Stress and Hyperlipidaemia
}

\author{
Irena Landeka Jurčević ${ }^{1}$ Mirna Dora ${ }^{1}$, Iva Guberović ${ }^{1}$, Marija Petras ${ }^{1}$, \\ Suzana Rimac Brnčić ${ }^{1}$ and Domagoj Đikić ${ }^{* *}$ \\ ${ }^{1}$ University of Zagreb, Faculty of Food Technology and Biotechnology, Pierottijeva 6, \\ HR-10000 Zagreb, Croatia \\ ${ }^{2}$ Faculty of Science, University of Zagreb, Rooseveltov trg 6, HR-10000 Zagreb, Croatia
}

Received: July 14, 2016 Accepted: October 13, 2016

\begin{abstract}
Summary
The study examines the potential of wine industry by-product, the lees, as a rich mixture of natural polyphenols, and its physiological potential to reduce postprandial metabolic and oxidative stress caused by a cholesterol-rich diet in in vivo model. Chemical analysis of wine lees showed that their total solid content was $94.2 \%$. Wine lees contained total phenols, total nonflavonoids and total flavonoids expressed in $\mathrm{mg}$ of gallic acid equivalents per $100 \mathrm{~g}$ of dry mass: $2316.6 \pm 37.9,1332.5 \pm 51.1$ and $984.1 \pm 28.2$, respectively. The content of total anthocyanins expressed in mg of cyanidin-3-glucoside equivalents per $100 \mathrm{~g}$ of dry mass was 383.1 \pm 21.6 . Antioxidant capacity of wine lees determined by the DPPH and FRAP methods and expressed in $\mathrm{mM}$ of Trolox equivalents per $100 \mathrm{~g}$ was $259.8 \pm 1.8$ and $45.7 \pm 1.05$, respectively. The experiment lasted 60 days using C57BL/6 mice divided in four groups: group 1 was fed normal diet and used as control, group 2 was fed normal diet with added wine lees, group 3 was fed high-cholesterol diet (HCD), i.e. normal diet with the addition of sunflower oil, and group 4 was fed HCD with wine lees. HCD increased serum total cholesterol (TC) by 2.3-fold, triacylglycerol (TAG) by 1.5-fold, low-density lipoprotein (LDL) by 3.5-fold and liver malondialdehyde (MDA) by $50 \%$, and reduced liver superoxide dismutase (SOD) by $50 \%$, catalase (CAT) by $30 \%$ and glutathione (GSH) by $17.5 \%$ compared to control. Conversely, treatment with HCD and wine lees reduced TC and LDL up to 1.4 times more than with HCD only, with depletion of lipid peroxidation (MDA) and restoration of SOD and CAT activities in liver, approximating values of the control. HDL levels were unaffected in any group. Serum transaminase activity showed no hepatotoxic properties in the treatment with lees alone. In the proposed model, wine lees as a rich polyphenol source could be a basis for functional food products without alcohol.
\end{abstract}

Key words: wine lees, lipoproteins, hyperlipidaemia, lipid peroxidation, antioxidants

\section{Introduction}

Wine lees are the residual precipitate formed during wine fermentation, storage, filtration or centrifugation (1). The (poly)phenolic compounds in lees determine the colour, intensity and organoleptic properties of wine. Through biochemical processes in lees, enzymatic activ- itiy induces the transformation of phenols to high value-added polyphenolic compounds with in vivo physiological activity, such as gallic acid or ellagic acid, catechin, caffeic acid, resveratrol and others (2-5). Several of these have been investigated individually or combined at the molecular level, e.g. the mechanisms of inhibition of nu- 
clear transcription factor $(\mathrm{NF})-\kappa \mathrm{B}$ induced by reactive oxygen species or activators of protein kinases, and are described as cancer chemoprevention substances, antioxidants, anti-inflammatory agents, and substances that improve glucose/lipid metabolism or prevent cardiovascular disease (CVD) (6-9).

CVD is currently the preeminent health issue worldwide and significant risk factors include hyperlipidaemia, high serum low-density lipoprotein (LDL) cholesterol and lipoprotein(a) levels, with low high-density (HDL) cholesterol (10-12). In 2013, the results of a large prospective randomised trial on stroke risks showed the benefits of a Mediterranean diet with moderate wine consumption in comparison with a low-fat diet. The study demonstrated a relative stroke risk reduction of 33-46 \%. Furthermore, other studies have shown that red wine consumption is inversely related to mortality from CVD, and cardioprotection has been observed with consumption levels up to $300 \mathrm{~mL}$ of wine per day $(13,14)$. In healthy individuals, the plasma concentrations of polyphenols increased in positive correlation with the phenolic content of consumed wine after just two weeks of consumption, indicating that wine polyphenols are successfully absorbed and bioavailable in humans and inhibit oxidative stress $(15,16)$. Polyphenols exert antioxidant properties to wine, and their effectiveness was demonstrated by Greenrod and Fenech (17), who reported a reduction $(>70 \%)$ of $\mathrm{H}_{2} \mathrm{O}_{2}$-induced genetic damage occurring just one hour after the consumption of $300 \mathrm{~mL}$ of red wine. In addition to the described antioxidant properties, wine polyphenols are known to reduce plasma triacylglycerol (TG) and total cholesterol (TC) levels, and elevate HDL concentrations, thereby reducing the risk of CVD (18).

Driven by the evidence of the beneficial health effects of wine consumption due to its polyphenol content, we hypothesised that the organic residue remaining after wine processing and the precipitation of lees might be a rich source of polyphenols and that such a raw, natural, compound mixture might be a polyphenol source that could play a positive physiological role against high cholesterol and lipid levels in the organism.

Furthermore, wine production is hampered by residual plant waste and large residual quantities pose an environmental risk. The disposal of organic waste containing more than $5 \%$ organic carbon is prohibited in the EU and is estimated that in Europe alone, 14.5 million tonnes of grape by-products are produced annually $(19,20)$. The results of this preliminary study might direct the reuse of such organic waste. The valorisation potential for this agroindustry by-product is currently supported by extensive information available on polyphenols in the context of health-promoting phytochemicals boasting a range of activites in the prevention of oxidative reactions, inflammatory processes and CVD in adults $(21,22)$.

The aim of this study is to investigate whether wine lees, as the residue of wine production, affect the lipid levels in the blood and antioxidative processes in liver in diet-induced hyperlipidaemia and hypercholesterolaemia. The study examines whether the qualitative and quantitative properties of polyphenols from wine lees and their in vitro antioxidative capacity, scarcely reported in the literature, reflect the in vivo physiological potential that is well known for wine consumption but not yet reported for wine less.

\section{Materials and Methods}

\section{Wine lees samples}

Wine lees were obtained directly from the Čitluk winery, Bosnia and Herzegovina (geographical location at N43.225708, E17.697295), as decanted sediment naturally occurring in the barrels/containers during the process of making Blatina wine in the 2014 production year. The freshly decanted thick, semiliquid precipitate was transported to the laboratory and kept at $4{ }^{\circ} \mathrm{C}$ until analysis. Lyophilisation of $100 \mathrm{~mL}$ of wine lees using Christ Gamma 1-16 LSC freeze dryer (Martin Christ GmbH, Osterode am Harz, Germany) gave $13 \mathrm{~g}$ of dry matter (dm).

\section{Determination of the physicochemical parameters of wine lees}

Total solid content of wine lees was determined using the gravimetric method. A sample of $(2 \pm 0.0001) \mathrm{g}$ of wine lees was mixed with about $5 \mathrm{~g}$ of sea sand and dried at $105^{\circ} \mathrm{C}$ until constant mass was achieved (23).

\section{Extraction of the phenolics from wine lees}

Approximately $2 \mathrm{~g}$ of wine lees were mixed with 10 $\mathrm{mL}$ of methanol/2 \% $\mathrm{HCl}$ (95:5, by volume) solution, and after $60 \mathrm{~min}$ the solution was filtered under vacuum. Extraction of the residue was repeated three times.

\section{Determination of total phenolic, nonflavonoid, total flavonoid and anthocyanin content of wine lees}

Total phenolic content was determined using the Folin-Ciocalteu method (24). An aliquot $(20 \mu \mathrm{L})$ of diluted extract of wine lees or standard solutions of gallic acid (25-500 mg/L) was mixed with $1580 \mu \mathrm{L}$ of distilled water and $100 \mu \mathrm{L}$ of Folin-Ciocalteu reagent. A volume of 300 $\mu \mathrm{L}$ of sodium carbonate solution $(200 \mathrm{~g} / \mathrm{L})$ was added to the mixture and vortexed, incubated at room temperature for $2 \mathrm{~h}$, and the absorbance was measured by the Libro S22 spectrophotometer (Biochrom, Cambourne, UK) at $\lambda=765 \mathrm{~nm}$ against the blind sample as a reference. The results of total phenolic content were calculated according to the calibration curve for gallic acid:

$$
y=0.00103 x-0.01128 ; R^{2}=0.99728
$$

where $\mathrm{y}$ is the absorbance at $765 \mathrm{~nm}$ and $\mathrm{x}$ is the concentration of gallic acid in $\mathrm{mg} / \mathrm{L}$.

Total phenolic content was expressed in mg of gallic acid equivalents (GAE) per $100 \mathrm{~g}$ of $\mathrm{dm}$.

Total flavonoid content was determined according to Ough and Amerine (25). A mixture of $3 \mathrm{~mL}$ of the extracted solution of wine lees, $1.5 \mathrm{~mL}$ of aqueous hydrochloric acid solution (1:4, by volume) and $3 \mathrm{~mL}$ of formaldehyde was injected into a stoppered flask filled with nitrogen gas to remove the air and left at $22{ }^{\circ} \mathrm{C}$ for $24 \mathrm{~h}$ in the dark, then filtered. The nonflavonoid phenolic compounds were 
determined with the Folin-Ciocalteu reagent after the removal of flavonoid phenolic compounds precipitated with formaldehyde. Then the total flavonoid content was calculated as the difference between the total polyphenolic content and total nonflavonoid content, expressed in $\mathrm{mg}$ of GAE per $100 \mathrm{~g}$ of $\mathrm{dm}$.

Total anthocyanin content, calculated as cyanidin-3-glucoside, was determined by the method of Giusti and Wrolstad (26). Two dilutions of the extract of wine lees were prepared, one with potassium chloride buffer $(\mathrm{pH}=$ $1.0)$, and the other with sodium acetate buffer $(\mathrm{pH}=4.5)$. After 15 min of incubation at room temperature, absorbance was measured simultaneously at wavelengths of 510 and $700 \mathrm{~nm}$ :

$$
A=\left(A_{510 \mathrm{~nm}}-A_{700 \mathrm{~nm}}\right)_{\mathrm{pH}=1.0}-\left(A_{510 \mathrm{~nm}}-A_{700 \mathrm{~nm}}\right)_{\mathrm{pH}=4.5}
$$

and the mass fraction of anthocyanins was calculated as follows:

$$
w(\text { anthocyanins })=\left(\frac{A}{\varepsilon \cdot l} \cdot M \cdot \mathrm{DF} \cdot \frac{V}{m}\right) \cdot 100
$$

where $A$ is absorbance, $\varepsilon$ is molar absorption coefficient of cyanidin-3-glucoside $(26900 \mathrm{~L} /(\mathrm{mol} \cdot \mathrm{cm})), l$ is cell path length $(1 \mathrm{~cm}), M$ is molar mass of cyanidin-3-glucoside $(449.2 \mathrm{~g} / \mathrm{mol}), \mathrm{DF}$ is dilution factor, $V$ is final volume $(\mathrm{mL})$, and $m$ is mass of the sample (mg). Results are expressed in $\mathrm{mg}$ of cyanidin-3-glucoside equivalents (CGE) per 100 $\mathrm{g}$ of $\mathrm{dm}$.

\section{Determination of total antioxidant capacity of wine lees by the DPPH method and ferric reducing antioxidant power}

The 2,2-diphenyl-1-picrylhydrazyl (DPPH) radical scavenging capacity was determined according to Brand-Williams et al. (27). A sample of $2 \mathrm{~mL}$ of extract of diluted wine lees or Trolox in methanol solution $(25-200 \mu \mathrm{mol} / \mathrm{L})$ was mixed with $2 \mathrm{~mL}$ of methanol and $1 \mathrm{~mL}$ of $0.5 \mathrm{mM}$ $\mathrm{DPPH}$ in methanol solution, vortexed and incubated in the dark for $20 \mathrm{~min}$, then the absorbance was measured at $517 \mathrm{~nm}$ against a methanol blank without the DPPH. The results were calculated according to the calibration curve for Trolox:

$$
y=-0.62525 x+1.33117 ; R^{2}=0.98171
$$

where $\mathrm{y}$ is the absorbance at $517 \mathrm{~nm}$ and $\mathrm{x}$ is the concentration of Trolox in $\mu \mathrm{mol} / \mathrm{L}$. DPPH values were expressed in $\mathrm{mmol}$ of TE per $100 \mathrm{~g}$ of $\mathrm{dm}$.

The ferric reducing antioxidant power (FRAP) assay was conducted according to Benzie and Strain (28). The FRAP reagent was prepared from $5 \mathrm{~mL}$ of 2,4,6-tripyridyl-s-triazine (TPTZ) solution $(10 \mathrm{mmol} / \mathrm{L})$ in $\mathrm{HCl}(40$ $\mathrm{mmol} / \mathrm{L})$ and $5 \mathrm{~mL}$ of $\mathrm{FeCl}_{3}$ solution $(20 \mathrm{mmol} / \mathrm{L})$ mixed with $50 \mathrm{~mL}$ of acetate buffer $(0.3 \mathrm{~mol} / \mathrm{L}, \mathrm{pH}=3.6)$. A volume of $2.08 \mathrm{~mL}$ of FRAP reagent was mixed with $240 \mu \mathrm{L}$ of water and $80 \mu \mathrm{L}$ of the diluted sample or standard solution of $\mathrm{FeSO}_{4} \cdot 7 \mathrm{H}_{2} \mathrm{O}(0.125-2.000 \mathrm{mmol} / \mathrm{L})$, incubated for $5 \mathrm{~min}$ at room temperature and then the absorbance was measured at $\lambda=595 \mathrm{~nm}$. FRAP values were calculated according to the calibration curve for $\mathrm{FeSO}_{4} \cdot 7 \mathrm{H}_{2} \mathrm{O}$ :

$$
y=0.72126 x-0.06396 ; R^{2}=0.99868
$$

where $\mathrm{y}$ is the absorbance at $595 \mathrm{~nm}$ and $\mathrm{x}$ is the concentration of $\mathrm{FeSO}_{4} \cdot 7 \mathrm{H}_{2} \mathrm{O}$ in $\mathrm{mmol} / \mathrm{L}$, and expressed in $\mathrm{mmol}$ of $\mathrm{Fe}^{2+}$ equivalents (FE) per $100 \mathrm{~g}$ of $\mathrm{dm}$.

\section{Extraction of samples for high-performance liquid chromatography}

A mass of $40 \mathrm{mg}$ of ascorbic acid was dissolved in 2.5 $\mathrm{mL}$ of redistilled water. The homogenised sample (1.0 $\mathrm{g}$ of lyophilised powder of wine less) was added to $12.5 \mathrm{~mL}$ of methanol and $5 \mathrm{~mL}$ of $6 \mathrm{M} \mathrm{HCl}$ and resuspended in $25 \mathrm{~mL}$ of methanol. Prior to injection into the high-performance liquid chromatograph (HPLC), the sample was filtered (filter pore size of $0.45 \mu \mathrm{m}$; Cameo Syringe, Sigma-Aldrich, St. Louis, MO, USA). The aforementioned solvents (methanol and acids) were of HPLC grade and purchased from J.T.Baker, Deventer, The Netherlands. The HPLC analysis of each sample was performed in triplicate. Phenolic acids and flavonoid standards, including ellagic, gallic, caffeic, p-coumaric and chlorogenic acids, kaempferol and quercetin were from Sigma-Aldrich. All standards were dissolved in methanol to a concentration of 1 $\mathrm{mg} / \mathrm{mL}$ and were stored in dark at $-20{ }^{\circ} \mathrm{C}$. The range of standards in water solution was (in $\mathrm{mg} / \mathrm{L}$ ): ellagic acid 3.196-318.000, gallic acid 1.005-100.000, caffeic acid 1.005100.000 , p-coumaric acid 3.216-320, chlorogenic acid 1.126112.000, kaempferol 0.221-22.000 and quercetin 3.216-320. Standards were filtered and analysed by chromatography under the same analytical conditions as the solution samples of wine lees in triplicate per each standard concentration. Based on the known concentration of the obtained chromatogram, the calibration curve was made.

Chromatographic separations were performed on a Zorbax Eclipse XDB-C18 column $(4.6 \mathrm{~mm} \times 250 \mathrm{~mm}, 5 \mu \mathrm{m}$; Agilent Technologies, Richardson, TX, USA). The column was placed in an oven at $20^{\circ} \mathrm{C}$. The HPLC was a Shimadzu (Kyoto, Japan) LC-10AD-vp series pumping system, with the refractive index detector RID-10A, a diode array detector SPD M10Avp, fluorescence detector RF-10Axl, vacuum degasser SGA-14A, system controller SCL-10Avp and the thermostat column CTO-10Asvp. Two solvents of HPLC grade were used with a constant flow rate of 0.8 $\mathrm{mL} / \mathrm{min}$. Solvent A consisted of $1 \%$ acetic acid in water and solvent B was methanol in water. For the elution program, the following fractions of solvent B were used: $5 \%$ B for $0-30 \mathrm{~min}, 80 \% \mathrm{~B}$ for $30-33 \mathrm{~min}$ and $5 \% \mathrm{~B}$ for $33-38$ $\min$.

Phenolic acids and flavonoids in the analysed samples of wine lees were identified and quantified on the basis of the prefabricated calibration curves of gallic acid ( $\mathrm{R}=0.9993)$, chlorogenic acid $(\mathrm{R}=0.9910)$, caffeic acid ( $\mathrm{R}=$ $0.9989), p$-coumaric acid $(R=0.9969)$, ellagic acid $(R=0.9928)$, quercetin $(\mathrm{R}=0.9988)$ and kaempferol $(\mathrm{R}=0.9991)$. Compounds were detected using a detector with diode array at wavelengths of $260 \mathrm{~nm}$ (ellagic acid), $280 \mathrm{~nm}$ (gallic acid), $320 \mathrm{~nm}$ (chlorogenic, caffeic and $p$-coumaric acids) and $360 \mathrm{~nm}$ (quercetin and kaempferol).

\section{In vivo study: animals and diets}

A total of 32 male inbred C57BL/6 mice, weighing 24 to $26 \mathrm{~g}$ were obtained from the Department of Animal Physiology, Faculty of Science, University of Zagreb, Cro- 
atia. They were fed a standard laboratory diet (4 RF 21; Mucedola S.R.L., Settimo Milanese, Italy) and tap water ad libitum and received 12 hours of light per day. Maintenance and care of all experimental animals was performed pursuant to the valid guidelines in the Republic of Croatia (29). The experimental procedure was approved by the Bioethics Committee of the Faculty of Science, University of Zagreb (30). The procedures were conducted according to the internationally accepted guidelines for the use of animals in in vivo experiments (31).

Animals were randomly divided in treatment groups and kept in group cages ( $N=8$ mice per group) and received daily treatments by oral gavage over a 60 -day period: group 1 (control) was fed normal diet with $0.2 \mathrm{~mL}$ of phosphate-buffered saline, group 2 animals received daily treatment of normal diet with the addition of wine lees in a dose of $1 \mathrm{~g} / \mathrm{kg}$, group 3 was fed high-cholesterol diet (HCD) containing suspension of $2 \%$ (mass per volume) cholesterol in $0.2 \mathrm{~mL}$ of sunflower oil, and group 4 was fed a combination of the diets of groups 2 and $3(0.2 \mathrm{~mL}$ of $2 \% \mathrm{HCD}$ with wine lees in a dose of $1 \mathrm{~g} / \mathrm{kg}$ ). The dose of wine lees was determined based on previous pilot trials conducted on three animals, when it was concluded that the optimal dose was $1 \mathrm{~g} / \mathrm{kg}$ per day, i.e. $0.2 \mathrm{~mL}$ of orally administered solution of wine lees (26 $\mathrm{mg}$ of dry matter per mouse), and that lower doses (diluted lees) had no effect.

\section{Serum and tissue preparations}

Blood was collected from the tail vein, the animals were sacrificed by cervical dislocation and the liver was extracted and weighed prior to freezing at $-80{ }^{\circ} \mathrm{C}$ until analysis. Tissue for the determination of malondialdehyde (MDA), superoxide dismutase (SOD), catalase (CAT) and glutathione $(\mathrm{GSH})$ was placed in $50 \mathrm{mM}$ phosphate buffer ( $\mathrm{pH}=7.4)$, homogenised (10\% by mass per volume) with the ultrasonic homogeniser SONOPULS HD2070 (Bandelin electronic GmbH \& Co. KG, Berlin, Germany) using a probe MS73 (Bandelin), sonicated on ice for $30 \mathrm{~s}$ in three 10 -second intervals and centrifuged at $20000 \times g$ for $15 \mathrm{~min}$ at $4{ }^{\circ} \mathrm{C}$. The supernatant was stored in plastic tubes at $-80^{\circ} \mathrm{C}$ until assayed.

\section{Determination of serum lipid content}

Serum was obtained by high speed centrifugation (15 min, 15 000×g, model 5424/5424 R microcentrifuge; Eppendorf, Hamburg, Germany) and stored at $-80^{\circ} \mathrm{C}$ until analysis. The concentrations of total cholesterol (TC), triacylglycerol (TAG), high-density cholesterol (HDL), and liver damage indices (aspartate aminotransferase (AST) and alanine aminotransferase (ALT) values) were measured by enzymatic colourimetric methods with commercial kits (Sigma-Aldrich) on an automatic analyser (Olympus 2700; Beckman Coulter Inc., Brea, CA, USA). Serum low-density lipoprotein (LDL) was calculated according to Friedewald et al. (32).

\section{Determination of protein}

Protein concentration in the samples was estimated by the method of Lowry et al. (33) with bovine serum albumin (BSA) as the standard. It was used to express the values of measured oxidative stress parameters.

\section{Markers of oxidative stress}

Lipid peroxidation was determined by measuring the concentration of MDA using a modified method of Ohkawa et al. (34). A sample of $200 \mu \mathrm{L}$ of homogenised tissue was mixed with aqueous solutions of $200 \mu \mathrm{L}$ of $8.1 \%$ sodium dodecyl sulphate (SDS), $1.5 \mathrm{~mL}$ of $20 \%$ acetic acid $(\mathrm{pH}=3.5)$ and $1.5 \mathrm{~mL}$ of $0.81 \%$ thiobarbituric acid, and incubated for $60 \mathrm{~min}$ at $95{ }^{\circ} \mathrm{C}$. After cooling on ice, the absorbance was measured at 532 and $600 \mathrm{~nm}$ with a Libro S22 spectrophotometer (Biochrom). Total absorbance was determined using the formula:

$$
A_{\text {total }}=A_{532 \mathrm{~nm}}-A_{600 \mathrm{~nm}}
$$

MDA levels were determined using molar absorption coefficient for malondialdehyde-thiobarbituric acid (MDA-TBA) complex of $1.56 \cdot 10^{5} \mathrm{M}^{-1} \mathrm{~cm}^{-1}$.

The SOD assay is a modification of the method proposed by Flohé and Ötting (35). The SOD activity was calculated from the percentage of inhibition of the reaction of xanthine oxidation $(\triangle A / \min \approx 0.025)$, which creates a superoxide anion as a substrate for the SOD present in the samples. The superoxide anion not used by the enzyme oxidises the cytochrome. An undiluted sample $(25 \mu \mathrm{L})$ was mixed with $1.45 \mathrm{~mL}$ of the reaction solution (cytochrome C $0.05 \mathrm{mM}$ and xanthine $1 \mathrm{mM}$ mixed in a 10:1 ratio with 5-5'-dithiobis[2-nitrobenzoic acid] (DTNB)). A volume of $20 \mu \mathrm{L}$ of xanthine oxidase $(0.4 \mathrm{U} / \mathrm{mL})$ was added to start the reaction. The reaction was measured for $3 \mathrm{~min}$ at 550 $\mathrm{nm}$ with a Libro S22 spectrophotometer (Biochrom). One unit of total SOD activity was defined as the amount of enzyme required to achieve $50 \%$ inhibition in the typical calibration curve obtained with standard SOD. Horse heart cytochrome C (type VI), human blood SOD (type I, lyophilised powder, $2400 \mathrm{U} / \mathrm{mg}$ protein), xanthine and xanthine oxidase $(200 \mathrm{U} / \mathrm{mL})$ were from Sigma-Aldrich.

The GSH assay is a modification of the method first described by Tietze (36). In a 96-well plate, $40 \mu \mathrm{L}$ of 10 mM DTNB (Ellman's reagent) were mixed with $20 \mu \mathrm{L}$ of sample supernatant pretreated with $40 \mu \mathrm{L}$ of $0.035 \mathrm{M}$ HCL, incubated for $10 \mathrm{~min}$ and measured at $412 \mathrm{~nm}$ in an ELISA plate reader (Bio-Rad Laboratories, Hercules, CA, USA). Then, $100 \mu \mathrm{L}$ of reaction solution containing: 9980 $\mu \mathrm{L}$ of $0.8 \mathrm{mM}$ NADPH and $20 \mu \mathrm{L}$ of glutathione reductase $(0.2 \mathrm{U} / \mathrm{mL})$ were added and the absorbance was read at $412 \mathrm{~nm}$ every minute for $5 \mathrm{~min}$. GSH levels were determined by using molar absorption coefficient for DTNB of $8.22 \mathrm{M}^{-1} \mathrm{~cm}^{-1}$. DTNB, NADPH and glutathione reductase were purchased from Sigma-Aldrich.

CAT activity in liver was assayed by measuring the initial rate of $\mathrm{H}_{2} \mathrm{O}_{2}$ disappearance at $240 \mathrm{~nm}$ with Libro S22 spectrophotometer (Biochrom) (37). The reaction mixture contained $33 \mathrm{mM} \mathrm{H} \mathrm{O}_{2}$ in $50 \mathrm{mM}$ phosphate buffer, $\mathrm{pH}=7.0$, and CAT activity was calculated using the molar absorption coefficient of $\mathrm{H}_{2} \mathrm{O}_{2}$ of $43.6 \mathrm{M}^{-1} \mathrm{~cm}^{-1}$.

\section{Statistical analysis}

Data are presented as mean values with standard deviations (S.D.). The data were tested for normality and homoscedasticity with the Shapiro-Wilks' W test. They were normally distributed and further tested by ANOVA 
and Tukey's post hoc test for detection of differences between the mean values. Statistical significance between the groups was set at $\mathrm{p}<0.05$. The analysis was performed using SPSS v. 17 software (38).

\section{Results and Discussion}

Research on dietary hyperlipidaemia and oxidative stress in vascular inflammation $(39,40)$ has been directed towards the development of new nutritional strategies and the creation of pharmaceuticals of wine-based origin that have the potential to reduce the development and adverse effect of cardiovascular disease (CVD). Previous studies showed that Blatina red wine contains very high concentrations of total phenols (1786.71-2235.59 mg/L) depending on maceration time $(41,42)$. In general, Blatina wine has a higher polyphenolic content than wines from other geographical origins (43), which was the main reason its lees were selected for this study.

Chemical analysis of wine lees showed that their total solid content was $94.2 \%$. Analysis of particular groups of bioactive compounds showed that wine lees contained total phenols, total nonflavonoids and total flavonoids expressed in mg of gallic acid equivalents per $100 \mathrm{~g}$ of dry mass: $2316.6 \pm 37.9,1332.5 \pm 51.1$ and $984.1 \pm 28.2$, respectively. The content of total anthocyanins expressed in $\mathrm{mg}$ of cyanidin-3-glucoside equivalents per $100 \mathrm{~g}$ of dry mass

Table 1. Content of polyphenols on dry mass basis determined in wine lees by HPLC method

\begin{tabular}{lc}
\hline Compound & $w /(\mathrm{mg} / 100 \mathrm{~g})$ \\
\hline Quercetin & $62.0 \pm 4.2$ \\
Ellagic acid & $21.9 \pm 2.3$ \\
$p$-Coumaric acid & $15.8 \pm 1.7$ \\
Gallic acid & $13.4 \pm 1.4$ \\
Caffeic acid & $12.8 \pm 1.4$ \\
Chlorogenic acid & $8.2 \pm 0.9$ \\
Kaempferol & $5.9 \pm 0.6$ \\
\hline
\end{tabular}

Results represent mean values \pm standard deviation (S.D.) of three independent measurements was 383.1 \pm 21.6 . The assessment of total antioxidant capacity of wine lees by the DPPH and FRAP methods, expressed in $\mathrm{mM}$ of Trolox equivalents per $100 \mathrm{~g}$ of dry mass, showed that DPPH antioxidant capacity was $259.8 \pm 1.8$ and FRAP was $45.70 \pm 1.05$. The reported HPLC analysis of Blatina red wine lees (Table 1) showed that amongst the most abundant polyphenols was quercetin in concentrations exceeding the amounts of other detected individual polyphenolic compounds almost three times. Ellagic acid was the second highest detected compound followed by approx. $28 \%$ lower concentrations of galic, caffeic and $p$-coumaric acids, all at approximately similar levels. Chlorogenic acid and kaempferol were present in smaller but similar concentrations. Data on the polyphenolic content of lees usually compare polyphenolic content as correlation between the length of maceration time and wine ageing $(41,42)$, and values are given only for the wine and not for the lees. Rare existing reports on qualitative and quantitative composition of polyphenols mention lower insoluble-bound fractions of 63 and $79 \%$ with a lower TPC of 5000-9000 $\mu \mathrm{g} / \mathrm{g}(44)$ and lower contents of polyphenolics, for example caffeic acid, $p$-coumaric acid, myricetin, quercetin and its glycans (45) than detected here. Results on total polyphenols and individual polyphenolic content justify the starting hypothesis that Blatina lees are a rich source of bioactive substances with high antioxidant activity suitable for in vivo physiological experiment.

In the in vivo study, feeding mice with a cholesterol-rich diet resulted in dietary hyperlipidaemia and hypercholesterolaemia, a known model in the literature (46). A hypercholesterolaemic high-fat diet significantly increased $(\mathrm{p}<0.05)$ TC by approx. 2.3 -fold, TAG by 1.5 -fold and LDL by 3.5-fold in comparison with a control, fed a normal diet (Table 2). However, treatment with wine lees together with fat and cholesterol-rich diet significantly $(\mathrm{p}<0.05)$ decreased TC, TAG and LDL (Table 2) compared to hypercholesterolaemic group treated without wine lees. In combined treatment with high-cholesterol diet and wine lees, TC and LDL did not reach the same levels as in animals fed a normal diet but were reduced by approx. 1.3- to 1.4-times more than in the treatment with high-cholesterol diet alone. There is no information in the literature about the effect of treatment with wine lees as a functional food on serum lipid levels. However, similar

Table 2. Serum lipid concentrations and serum enzyme activity at normocholesterolaemic diet and hypercholesterolaemic diet in treated mice

\begin{tabular}{|c|c|c|c|c|}
\hline \multirow{2}{*}{$\gamma($ serum lipid $) /(\mathrm{mg} / \mathrm{dL})$} & \multicolumn{2}{|c|}{ Normocholesterolaemic diet } & \multicolumn{2}{|c|}{ Hypercholesterolaemic diet } \\
\hline & Control & Wine lees & Cholesterol & Wine lees+cholesterol \\
\hline TC & $(81.1 \pm 5.8)^{\mathrm{a}}$ & $(78.1 \pm 5.6)^{\mathrm{a}}$ & $(185.2 \pm 6.2)^{b}$ & $(143.3 \pm 5.7)^{\mathrm{c}}$ \\
\hline TAG & $(61.8 \pm 6.1)^{\mathrm{a}}$ & $(50.7 \pm 6.9)^{\mathrm{b}}$ & $(89.9 \pm 7.2)^{c}$ & $(59.9 \pm 7.1)^{a}$ \\
\hline LDL & $(38.5 \pm 6.8)^{\mathrm{a}}$ & $(36.7 \pm 6.2)^{\mathrm{a}}$ & $(134.8 \pm 6.6)^{b}$ & $(94.2 \pm 6.4)^{c}$ \\
\hline HDL & $30.9 \pm 4.8$ & $31.3 \pm 4.8$ & $32.4 \pm 5.2$ & $37.1 \pm 4.9$ \\
\hline \multicolumn{5}{|c|}{ Serum enzyme activity/(U/mL) } \\
\hline AST & $(56.2 \pm 3.4)^{\mathrm{a}}$ & $(55.1 \pm 3.4)^{\mathrm{a}}$ & $(75.1 \pm 3.6)^{\mathrm{b}}$ & $(56.9 \pm 3.2)^{\mathrm{a}}$ \\
\hline ALT & $(27.3 \pm 3.2)^{\mathrm{a}}$ & $(26.8 \pm 3.2)^{\mathrm{a}}$ & $(36.4 \pm 3.7)^{\mathrm{b}}$ & $(25.1 \pm 3.6)^{\mathrm{a}}$ \\
\hline
\end{tabular}

Values are expressed as mean \pm S.D. TC=total cholesterol, TAG=triacylglycerol, LDL=low-density lipoprotein, HDL=high-density lipoprotein, AST=aspartate aminotransferase, ALT=alanine aminotransferase. Mean values with different letters in superscript are significantly different $(\mathrm{p}<0.05)$ 
reduction of hypocholesterolaemic and hypotriglyceridaemic effects has been reported for polyphenol-rich wine and other foods and beverages in similar in vivo experiments (47-51). The results presented here can be explained by the proposed mechanisms from similar studies that polyphenols from wine or other plant sources alter the lipoprotein metabolism by mechanisms of delayed lymphoid transport, influencing apolipoprotein B concentrations, packaging and secretion of very low-density lipoprotein particles from the liver or expression of LDL receptors (49-51). This remains to be elucidated in future mechanistic and physiological studies on polyphenols in wine lees. The proposed effects do not mention the increase of serum HDL levels as a possible mechanism of cholesterol reorganisation in the organism. Our results also showed this trend of unchanged HDL levels regardless of the treatment (Table 2).

Regarding the oxidative and antioxidative processes in the liver, it was shown that a dietary stressor such as a hypercholesterolaemic diet was able to induce post-prandial metabolic stress, which mediated an imbalance of the oxidoreduction pathways and a burst of lipid peroxidation recorded through the formation of MDA (Fig. 1a) in liver tissue. These effects can be explained by mitochondrial activity, as in some previous studies (52). A significant $(\mathrm{p}<0.05)$ decrease in the activities of SOD by approx. $50 \%$ (Fig. 1b), CAT by approx. 30 \% (Fig. 1c) and glutathione by approx. $17.5 \%$ was observed in mice treated with HCD (Table 3). Conversely, mice on a HCD simultaneously fed a diet enriched with wine lees showed a significant $(p<0.05)$ depletion of lipid peroxidation in liver tissue (Fig. 1a), which has been shown similarly in the literature for other polyphenol-rich foods $(47,50,51,53)$. Furthermore, there was a significant $(p<0.05)$ restoration of hepatic SOD and CAT activities (Figs. $1 b$ and c), with the values similar to the control group. The composition and high content of polyphenols in lees are likely responsible for diminishing oxidative stress and for the reduced activity of antioxidant enzymes. A likely mechanism might be in the ROS reaction with protein thiol moieties to produce a variety of sulphur oxidation states, thus lowering LDL oxidation and acting as a scavenger of single-electron oxidants, inhibiting lipid peroxidation $(50,51)$. Some studies on wine antioxidant effects and the beneficial influence of wine consumption on serum lipids and antioxidant enzymes state that lipid- and cholesterol-lowering properties may be physiologically elicited by the alcohol component of wine rather than polyphenols, since alcohol metabolism is associated with increased HDL cholesterol levels and stimulates reverse cholesterol transport (49). However, the results of this study indicate that a similar effect is also obtained without alcohol component.
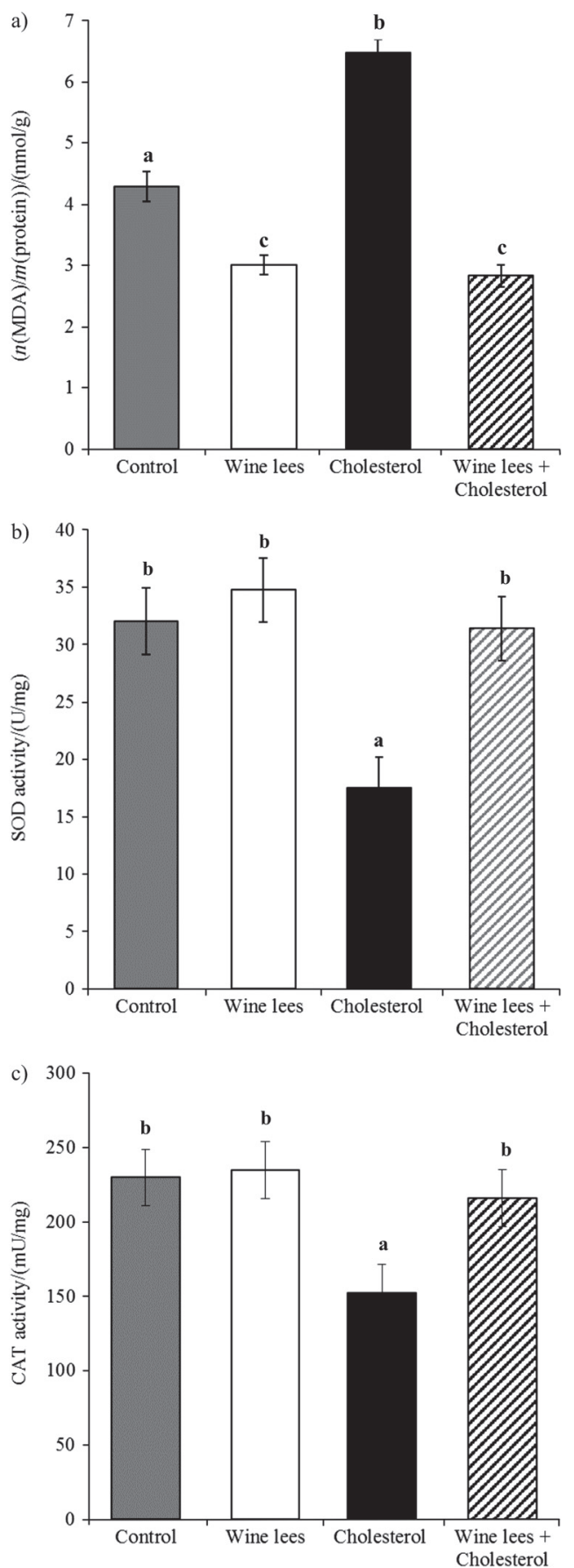

Fig. 1. Liver levels of: a) malondialdehyde (MDA), b) superoxide dismutase (SOD), and c) catalase (CAT). Values are expressed as mean $\pm S$.D. Values with different letters are significantly different $(\mathrm{p}<0.05)$

Table 3. Activity of liver antioxidant glutathione in mice fed normocholesterolaemic diet and hypercholesterolaemic diet

\begin{tabular}{|c|c|c|c|c|}
\hline Activity & Normoc & nic diet & Hyperc & olaemic diet \\
\hline$\overline{\mu \mathrm{M} / \mathrm{mg} \text { of protein }}$ & Control & Wine lees & Cholesterol & Wine lees+cholesterol \\
\hline GSH & $(20.5 \pm 0.3)^{a}$ & $(24.2 \pm 0.3)^{\mathrm{b}}$ & $(16.9 \pm 0.4)^{c}$ & $(22.1 \pm 0.3)^{a}$ \\
\hline GSSG & $(0.3 \pm 0.06)^{\mathrm{a}}$ & $(0.2 \pm 0.08)^{\mathrm{b}}$ & $(0.3 \pm 0.08)^{\mathrm{a}}$ & $(0.3 \pm 0.06)^{\mathrm{b}}$ \\
\hline GSH/GSSG & $(62.1 \pm 12.1)^{\mathrm{a}}$ & $(89.6 \pm 10.2)^{\mathrm{b}}$ & $(49.7 \pm 15.3)^{c}$ & $(76.2 \pm 13.5)^{\mathrm{d}}$ \\
\hline
\end{tabular}

Values are expressed as mean \pm S.D. GSH=reduced glutathione, GSSG=glutathione disulfide.

Mean values with different letters in superscript are significantly different $(p<0.05)$ 
A hypercholesterolaemic diet significantly $(\mathrm{p}<0.05)$ increased plasma liver metabolic transaminase markers AST and ALT (Table 2). When wine lees are added to the diet, the activity of these enzymes was restored and was close to the values of the control group, but treatment with lees alone did not elicit the increase of these biomarkers in serum (Table 2). Based on the survey of basic liver enzymes, the application of lees as a food supplement could be considered safe within the proposed animal model, although a broad risk study should be conducted to confirm these preliminary results prior to conducting applicative trials.

\section{Conclusions}

This preliminary study showed that the lees remaining after Blatina wine precipitation are rich in polyphenols and antioxidant bioactive compounds with hypolipidaemic and antioxidant properties in dietary-induced hypercholesterolaemia in animal model. High phenolic content and antioxidant capacity suggest that the wine lees are a potent source for the development of antioxidants from wine by-products. Evidence in humans of the same physiological properties should be collected to allow polyphenols from wine lees to be developed as an efficient functional food. Nevertheless, this study indicates that polyphenols isolated from wine lees present a potential dietary source of antioxidants without alcohol consumption.

\section{Acknowledgements}

The study was supported by the Department of Animal Physiology, Faculty of Science, University of Zagreb, Croatia (project of the Ministry of Science and Education no. 119-0000000-1255) and the Croatian Academy of Science and Arts (MetCholOx 2015).

\section{References}

1. Fia G, Zanoni B, Gori C. A new technique for exploitation of wine lees. Agric Agric Sci Procedia. 2016;8:748-54. http://dx.doi.org/10.1016/j.aaspro.2016.02.060

2. Vattem DA, Shetty K. Ellagic acid production and phenolic antioxidant activity in cranberry pomace (Vaccinium macrocarpon) mediated by Lentinus edodes using a solid-state system. Process Biochem. 2003;39:367-79. http://dx.doi.org/10.1016/S0032-9592(03)00089-X

3. Mazauric JP, Salmon JM. Interactions between yeast lees and wine polyphenols during simulation of wine aging. II. Analysis of desorbed polyphenol compounds from yeast lees. J Agric Food Chem. 2006;54:3876-81. http://dx.doi.org/10.1021/jf060037o

4. Giovinazzo G, Grieco F. Functional properties of grape and wine polyphenols. Plant Foods Hum Nutr. 2015;70:454-62. http://dx.doi.org/10.1007/s11130-015-0518-1

5. Ratola N, Faria JL, Alves A. Analysis and quantification of trans-resveratrol in wines from Alentejo Region (Portugal). Food Technol Biotechnol. 2004;42:125-30.

6. Cai YJ, Fang JG, Ma LP, Yang L, Liu ZL. Inhibition of free radical-induced peroxidation of rat liver microsomes by resveratrol and its analogues. BBA - Mol Basis Dis. 2003;1637: $31-8$.

http://dx.doi.org/10.1016/S0925-4439(02)00174-6
7. Milde J, Elstner EF, Grabmann J. Synergistic effects of polyphenols and carotenoids on human low-density lipoprotein oxidation. Mol Nutr Food Res. 2007;51:956-61.

http://dx.doi.org/10.1002/mnfr.200600271

8. Park CE, Kim MJ, Lee JH, Min BI, Bae H, Choe W, et al. Resveratrol stimulates glucose transport in $\mathrm{C} 2 \mathrm{C} 12$ myotubes by activating AMP-activated protein kinase. Exp Mol Med. 2007; 39:222-9.

http://dx.doi.org/10.1038/emm.2007.25

9. Oak MH, El Bedoui J, Schini-Kerth VB. Antiangiogenic properties of natural polyphenols from red wine and green tea. J Nutr Biochem. 2005;16:1-8. http://dx.doi.org/10.1016/j.jnutbio.2004.09.004

10. Morton LW, Abu-Amsha Caccetta R, Puddey IB, Croft KD. Chemistry and biological effects of dietary phenolic compounds: relevance to cardiovascular disease. Clin Exp Pharmacol Physiol. 2000;27:152-9.

http://dx.doi.org/10.1046/j.1440-1681.2000.03214.x

11. Raza JA, Babb JD, Movahed A. Optimal management of hyperlipidemia in primary prevention of cardiovascular disease. Int J Cardiol. 2004;97:355-66. http://dx.doi.org/10.1016/j.ijcard.2003.07.039

12. Enkhmaa B, Anuurad E, Zhang W, Tran T, Berglund L. Lipoprotein(a): genotype-phenotype relationship and impact on atherogenic risk. Metab Syndr Relat Disord. 2011;9:411-8. http://dx.doi.org/10.1089/met.2011.0026

13. Huxley RR, Barzi F, Lam TH, Czernichow S, Fang X, Welborn $\mathrm{T}$, et al. Isolated low levels of high-density lipoprotein cholesterol are associated with an increased risk of coronary heart disease: an individual participant data meta-analysis of 23 studies in the Asia-Pacific region. Circulation. 2011;124: 2056-64. http://dx.doi.org/10.1161/CIRCULATIONAHA.111.028373

14. Estruch R, Ros E, Salas-Salvadó J, Covas MI, Corella D, Arós F, et al. Primary prevention of cardiovascular disease with a Mediterranean diet. N Engl J Med. 2013;368:1279-90. http://dx.doi.org/10.1056/NEJMoa1200303

15. Grønbæk M. Alcohol, type of alcohol, and all-cause and coronary heart disease mortality. Ann NY Acad Sci. 2002;957:1620. http://dx.doi.org/10.1111/j.1749-6632.2002.tb02902.x

16. Pignatelli P, Ghiselli A, Buchetti B, Carnevale R, Natella F, Germanò $G$, et al. Polyphenols synergistically inhibit oxidative stress in subjects given red and white wine. Atherosclerosis. 2006;188:77-83.

http://dx.doi.org/10.1016/j.atherosclerosis.2005.10.025

17. Greenrod W, Fenech M. The principal phenolic and alcoholic components of wine protect human lymphocytes against hydrogen peroxide- and ionizing radiation-induced DNA damage in vitro. Mutagenesis. 2003;18:119-26. http://dx.doi.org/10.1093/mutage/18.2.119

18. Joshi SC, Jain PK. A review on hypolipidaemic and antioxidant potential of some medicinal plants. WJPPS. 2014;3:35780.

19. Devesa-Rey R, Vecino X, Varela-Alende JL, Barral MT, Cruz $\mathrm{JM}$, Moldes AB. Valorization of winery waste vs. the costs of not recycling. Waste Manage. 2011;31:2327-35. http://dx.doi.org/10.1016/j.wasman.2011.06.001

20. Council Directive 1999/31/EC of 26 April 1999 on the landfill of waste. Official Journal L. 1999;182:0001-19. Available from: http://eur-lex.europa.eu/legal-content/EN/TXT/?uri=CELEX: 31999L0031.

21. Shrikhande AJ. Wine by-products with health benefits. Food Res Int. 2000;33:469-74. http://dx.doi.org/10.1016/S0963-9969(00)00071-5

22. Negro C, Tommas L, Miceli A. Phenolic compounds and antioxidant activity from red grape marc extracts. Bioresour 
Technol. 2003;87:41-4

http://dx.doi.org/10.1016/S0960-8524(02)00202-X

23. AOAC Official Methods of Analysis. Rockville, MD, USA: AOAC International; 2000.

24. Waterhouse AL. Determination of total phenolics. In: Wrolstad RE, editor. Current protocols in food analytical chemistry. New York, NY, USA: John Wiley and Sons, Inc; 2002. pp. I1.1.1-8.

25. Ough CS, Amerine MA. Methods for analysis of musts and wines. New York, NY, USA: John Wiley and Sons, Inc; 1988.

26. Giusti MM, Wrolstad RE. Characterization and measurement of anthocyanins by UV-visible spectroscopy. In: Wrolstad RE, editor. Current protocols in food analytical Chemistry. New York, NY, USA: John Wiley and Sons, Inc; 2001. pp. F1.2.2-13.

27. Brand-Williams W, Cuvelier ME, Berset C. Use of a free radical method to evaluate antioxidant activity. LWT - Food Sci Technol. 1995;28:25-30.

http://dx.doi.org/10.1016/S0023-6438(95)80008-5

28. Benzie IFF, Strain JJ. The ferric reducing ability of plasma (FRAP) as a measure of antioxidant power: the FRAP assay. Anal Biochem. 1996;239:70-6. http://dx.doi.org/10.1006/abio.1996.0292

29. Act on Animal Welfare No. 135. Zagreb, Croatia: Official Gazette of the Republic of Croatia; 2006 (in Croatian).

30. Bioethic approval of the experimental procedure within the project, Document No. 251-58-10617-14-37. Zagreb, Croatia: Faculty of Science, University of Zagreb; 2014 (in Croatian).

31. Guide for the care and use of laboratory animals. Washington DC, USA: National Academies Press; 2011. pp. 86-123.

32. Friedewald WT, Levy RI, Fredrickson DS. Estimation of the concentration of low-density lipoprotein cholesterol in plasma without preparative ultracentrifuge. Clin Chem. 1972;18: 499-502.

33. Lowry OH, Rosebrough NJ, Farr AL, Randall RJ. Protein measurement with the Folin phenol reagent. J Biol Chem. 1951;193:265-75.

34. Ohkawa H, Ohishi N, Yagi K. Assay for lipid peroxides in animal tissues by thiobarbituric acid reaction. Anal Biochem. 1979;95:351-8. http://dx.doi.org/10.1016/0003-2697(79)90738-3

35. Flohé L, Ötting F. Superoxide dismutase assays. In: Packer L, editor. Methods in enzymology, vol. 105. Amsterdam, The Netherlands: Elsevier Inc.; 1984. pp. 93-104. http://dx.doi.org/10.1016/S0076-6879(84)05013-8

36. Tietze F. Enzymic method for quantitative determination of nanogram amounts of total and oxidized glutathione: applications to mammalian blood and other tissues. Anal Biochem. 1969;27:502-22. http://dx.doi.org/10.1016/0003-2697(69)90064-5

37. Aebi H. Catalase in vitro. In: Packer L, editor. Methods in enzymology, vol. 105. Amsterdam, The Netherlands: Elsevier Inc.; 2008. pp. 121-6. http://dx.doi.org/10.1016/S0076-6879(84)05016-3

38. SPSS v. 17.0, SPSS Inc, Chicago, IL, USA. Available from: https://www.hks.harvard.edu/fs/pnorris/Classes/.

39. Chiva-Blanch G, Arranz S, Lamuela-Raventos RM, Estruch R. Effects of wine, alcohol and polyphenols on cardiovascular disease risk factors: evidences from human studies. Alcohol Alcohol. 2013;48:270-7. http://dx.doi.org/10.1093/alcalc/agt007
40. Rodrigo R, Miranda A, Vergara L. Modulation of endogenous antioxidant system by wine polyphenols in human disease. Clin Chim Acta. 2011;412:410-24. http://dx.doi.org/10.1016/j.cca.2010.11.034

41. Herjavec S, Jeromel A, Maslov L, Jagatić Korenika AM, Mihaljević M, Prusina T. Influence of different maceration times on the anthocyanin composition and sensory properties of Blatina wines. Agric Conspec Sci. 2012;77:41-4.

42. Pérez-Serradilla JA, Luque de Castro MD. Role of lees in wine production: a review. Food Chem. 2008;111:447-56. http://dx.doi.org/10.1016/j.foodchem.2008.04.019

43. Granato D, Chizuko Uchida Katayama F, Alves de Castro I. Phenolic composition of South American red wines classified according to their antioxidant activity, retail price and sensory quality. Food Chem. 2011;129:366-73. http://dx.doi.org/10.1016/j.foodchem.2011.04.085

44. de Camargo AC, Regitano-d'Arce MAB, Biasoto ACT, Shahidi F. Low molecular weight phenolics of grape juice and winemaking byproducts: antioxidant activities and inhibition of oxidation of human low-density lipoprotein cholesterol and DNA strand breakage. J Agric Food Chem. 2014;62: 12159-71. http://dx.doi.org/110.1021/jf504185s.

45. Teixeira A, Baenas N, Dominguez-Perles R, Barros A, Rosa E, Moreno DA,Garcia-Viguera C. Natural bioactive compounds from winery by-products as health promoters: a review. Int J Mol Sci. 2014;15:15638-78. http://dx.doi.org/10.3390/ijms150915638

46. Fazio S, Linton MF. Mouse models of hyperlipidemia and atherosclerosis. Front Biosci. 2001;6:D515-25.

47. Aprikian O, Busserolles J, Manach C, Mazur A, Morand C, Davicco MJ, et al. Lyophilized apple counteracts the development of hypercholesterolemia, oxidative stress, and renal dysfunction in obese Zucker rats. J Nutr. 2002;132:1969 -76 .

48. Naissides M, Mamo JCL, James AP, Pal S. The effect of acute red wine polyphenol consumption on postprandial lipidemia in postmenopausal women. Atherosclerosis. 2004;177: 401-8. http://dx.doi.org/10.1016/j.atherosclerosis.2004.07.025

49. Ikeda I, Tsuda K, Suzuki Y, Kobayashi M, Unno T, Tomoyori $\mathrm{H}$, et al. Tea catechins with a galloyl moiety suppress postprandial hypertriacylglicerolemia by delaying lymphatic transport of dietary fat in rats. J Nutr. 2005;135:155-9.

50. Lecumberri E, Goya L, Mateos R, Alía M, Ramos S, Izquierdo-Pulido M, Bravo L. A diet rich in dietary fiber from cocoa improves lipid profile and reduces malondialdehyde in hypercholesterolemic rats. Nutrition. 2007;23:332-41. http://dx.doi.org/10.1016/j.nut.2007.01.013

51. Patalay M, Lofgren IE, Freake HC, Koo SI, Fernandez ML. The lowering of plasma lipids following a weight reduction program is related to increased expression of the LDL receptor and lipoprotein lipase. J Nutr. 2005;135:735-9.

52. Alberici LC, Vercesi AE, Oliveira HCF. Mitochondrial energy metabolism and redox responses to hypertriglyceridemia. J Bioenerg Biomembr. 2011;43:19-23. http://doi.org/10.1007/s10863-011-9326-y

53. Molina MF, Sanchez-Reus I, Iglesias I, Benedi J. Quercetin, a flavonoid antioxidant, prevents and protects against ethanol-induced oxidative stress in mouse liver. Biol Pharm Bull. 2003;26:1398-402. http://doi.org/10.1248/bpb.26.1398 